\title{
Accurate measurement of unsteady state fluid temperature
}

\author{
Magdalena Jaremkiewicz ${ }^{1}$
}

Received: 20 November 2015 / Accepted: 28 June 2016 / Published online: 6 July 2016

(C) The Author(s) 2016. This article is published with open access at Springerlink.com

\begin{abstract}
In this paper, two accurate methods for determining the transient fluid temperature were presented. Measurements were conducted for boiling water since its temperature is known. At the beginning the thermometers are at the ambient temperature and next they are immediately immersed into saturated water. The measurements were carried out with two thermometers of different construction but with the same housing outer diameter equal to $15 \mathrm{~mm}$. One of them is a K-type industrial thermometer widely available commercially. The temperature indicated by the thermometer was corrected considering the thermometers as the first or second order inertia devices. The new design of a thermometer was proposed and also used to measure the temperature of boiling water. Its characteristic feature is a cylinder-shaped housing with the sheath thermocouple located in its center. The temperature of the fluid was determined based on measurements taken in the axis of the solid cylindrical element (housing) using the inverse space marching method. Measurements of the transient temperature of the air flowing through the wind tunnel using the same thermometers were also carried out. The proposed measurement technique provides more accurate results compared with measurements using industrial thermometers in conjunction with simple temperature correction using the inertial thermometer model of the first or second order. By comparing the results, it was demonstrated that the new thermometer allows obtaining the fluid temperature much faster and with higher accuracy in
\end{abstract}

Magdalena Jaremkiewicz

mjaremkiewicz@pk.edu.pl

Institute of Thermal Power Engineering, Cracow University of Technology, al. Jana Pawła II 37, PL-31-864 Cracow, Poland comparison to the industrial thermometer. Accurate measurements of the fast changing fluid temperature are possible due to the low inertia thermometer and fast space marching method applied for solving the inverse heat conduction problem.

\begin{tabular}{|c|c|}
\hline \multicolumn{2}{|c|}{ Abbreviations } \\
\hline$c(T)$ & Specific heat of the thermometer material $(\mathrm{J} /(\mathrm{kgK})$ \\
\hline$c_{p a}$ & $\begin{array}{l}\text { Specific heat of the air at constant pressure } \\
(\mathrm{J} /(\mathrm{kgK}))\end{array}$ \\
\hline$C S$ & Control volume surface \\
\hline$d$ & Outer diameter of the thermometer, $\mathrm{d}=2 r_{\text {out }}(\mathrm{m})$ \\
\hline$h$ & Heat transfer coefficient $\left(\mathrm{W} /\left(\mathrm{m}^{2} \mathrm{~K}\right)\right)$ \\
\hline$k_{a}$ & Air thermal conductivity $(\mathrm{W} /(\mathrm{mK}))$ \\
\hline$k(T)$ & $\begin{array}{l}\text { Thermal conductivity of the thermometer material } \\
(\mathrm{W} /(\mathrm{mK}))\end{array}$ \\
\hline $\mathbf{n}$ & $\begin{array}{l}\text { Normal unit surface vector directed towards the } \\
\text { outside }\end{array}$ \\
\hline $\mathrm{Nu}_{a}$ & Nusselt number, $\mathrm{Nu}_{a}=h d / k_{a}$ \\
\hline $\operatorname{Pr}_{a}$ & Prandtl number, $\operatorname{Pr}_{a}=c_{p a} \mu_{a} / k_{a}$ \\
\hline$\dot{\mathbf{q}}$ & Heat flux vector \\
\hline$\dot{q}_{v}$ & $\begin{array}{l}\text { Energy generation rate per unit volume (uniform } \\
\text { within the body) }\left(\mathrm{W} / \mathrm{m}^{3}\right)\end{array}$ \\
\hline$\dot{Q}_{i, j}$ & Heat flow rate between the nodes $i$ and $j(\mathrm{~W})$ \\
\hline $\operatorname{Re}_{a}$ & Reynolds number, $\operatorname{Re}_{a}=w d / \nu_{a}$ \\
\hline 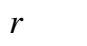 & Radius (m) \\
\hline$r_{\text {out }}$ & Outer radius of the thermometer $(\mathrm{m})$ \\
\hline$S$ & Surface area $\left(\mathrm{m}^{2}\right)$ \\
\hline$t$ & Time (s) \\
\hline$T(t)$ & Temperature $\left({ }^{\circ} \mathrm{C}\right)$ \\
\hline$T_{0}$ & Initial temperature $\left({ }^{\circ} \mathrm{C}\right)$ \\
\hline$T_{f}(t)$ & Fluid temperature $\left({ }^{\circ} \mathrm{C}\right)$ \\
\hline$T_{i}(t)$ & $\begin{array}{l}\text { Temperature at the node located inside the cell } \\
\text { under consideration }\left({ }^{\circ} \mathrm{C}\right)\end{array}$ \\
\hline & Response to the unit step \\
\hline
\end{tabular}

\section{Abbreviations}

(I) Specific heat of the thermometer material $(\mathrm{J} /(\mathrm{kgK}))$

CS Control volume surface

$d \quad$ Outer diameter of the thermometer, $\mathrm{d}=2 r_{\text {out }}(\mathrm{m})$

$h \quad$ Heat transfer coefficient $\left(\mathrm{W} /\left(\mathrm{m}^{2} \mathrm{~K}\right)\right)$

$k_{a} \quad$ Air thermal conductivity $(\mathrm{W} /(\mathrm{mK}))$

$k(T) \quad$ Thermal conductivity of the thermometer material $(\mathrm{W} /(\mathrm{mK}))$

n Normal unit surface vector directed towards the

$\operatorname{Pr}_{a} \quad$ Prandtl number, $\operatorname{Pr}_{a}=c_{p a} \mu_{a} / k_{a}$

$\dot{\mathbf{q}} \quad$ Heat flux vector

$\dot{q}_{v} \quad$ Energy generation rate per unit volume (uniform within the body) $\left(\mathrm{W} / \mathrm{m}^{3}\right)$

$Q_{i, j} \quad$ Heat flow rate between the nodes $i$ and $j(\mathrm{~W})$

$\operatorname{Re}_{a} \quad$ Reynolds number, $\operatorname{Re}_{a}=w d / \nu_{a}$

$r \quad$ Radius $(\mathrm{m})$

$r_{\text {out }} \quad$ Outer radius of the thermometer $(\mathrm{m})$

$S \quad$ Surface area $\left(\mathrm{m}^{2}\right)$

$t \quad$ Time (s)

$T(t) \quad$ Temperature $\left({ }^{\circ} \mathrm{C}\right)$

$T_{0} \quad$ Initial temperature $\left({ }^{\circ} \mathrm{C}\right)$

$T_{f}(t) \quad$ Fluid temperature $\left({ }^{\circ} \mathrm{C}\right)$

$T_{i}(t) \quad$ Temperature at the node located inside the cell

$u(t) \quad$ Response to the unit step 
$v_{T} \quad$ Rate of temperature change $(\mathrm{K} / \mathrm{s})$

$w \quad$ Velocity of the air $(\mathrm{m} / \mathrm{s})$

\section{Greek symbols}

$\Delta r \quad$ Spatial step in the $r$ direction (m)

$\Delta t \quad$ Time step (s)

$\Delta V_{i} \quad$ Volume of single cell (control volume) $\left(\mathrm{m}^{3}\right)$

$\varepsilon \quad$ Iteration tolerance $(\mathrm{K})$

$\kappa \quad$ Thermal diffusivity $\left(\mathrm{m}^{2} / \mathrm{s}\right)$

$\mu_{a} \quad$ Dynamic viscosity of the air (Pa s)

$v_{a} \quad$ Kinematic viscosity of the air $\left(\mathrm{m}^{2} / \mathrm{s}\right)$

$\rho(T) \quad$ Density $\left(\mathrm{kg} / \mathrm{m}^{3}\right)$

$\tau \quad$ Time constant of the first order inertial model (s)

$\tau_{1}, \tau_{2}$ Time constants of the second order inertial model

(s)

\section{Introduction}

The temperature measurement is an important and widely used measurement in industrial processes [1, 2]. Various techniques are used to measure the transient temperature of the fluid and the solid surface. One of the most commonly used measurement techniques is based on the use of liquid crystals. Heiland et al. [3] studied experimentally flow and temperature field measurements in a small vertical gap using liquid crystals. Thermochromic liquid crystals particles are dispersed in the fluid flow. The crystal particles change their reflected colour with temperature. Stephan and Fuchs measured local heat temperature fluctuations in wall and fluid in nucleate boiling systems using unencapsulated thermochromic liquid crystals with high spatial and temporal resolution [4]. The instantaneous shape of a growing bubble and the temperature of the liquid crystals beneath the bubble were observed with a high-speed camera. The method of liquid crystals is very useful in the laboratory.

Under steady-state conditions when the fluid temperature is constant, there is no damping and time lag and temperature measurement can be made with high accuracy. When the fluid temperature changes over time, the response time of thermometer can be very long, depending on the type of thermometer and the outer diameter of its housing [1, 2, 5-8].

Even if thermocouples or resistance thermometers are thin, dynamic temperature measurement errors can be large $[9,10]$. Modeling the thermocouple as an inertial object of the first or second order dynamic temperature measurement errors can be greatly reduced [10]. The techniques presented in the paper [10] take into account the dependence of the thermometer time constant on the fluid velocity.

Thick thermowell must be used in an industrial environment when the fluid temperature is measured at high pressure and high flow rate [5-8]. Thermometer housing must be robust because of the risk of damage to the thermometer due to fatigue. Vibrations of the thermometer pocket are caused by Karman vortices, which appear behind the thermometer [6]. During time variations of the fluid temperature, the thermal inertia of the housing has a significant influence on the measured values. Temperature sensor readings are delayed and attenuated compared to changes in temperature of the fluid. Thermocouples or resistance sensors are located in a housing containing ceramic insulating elements. The increase in the time constant of the thermometer is also due to a large air gap between the sensor and the housing. Accurate measurement of transient fluid temperature is required for proper operation of temperature control systems. Also during the start-up of large steam boilers dynamic errors of temperature measurement should be very small to carry out the optimum heating or cooling of thick-walled pressure elements $[11,12]$.

Accurate measurement of transient fluid temperature is also important in power plants, refineries, and chemical plants. Proper measurement of fluid temperature can prevent overheating of materials from which pipes and pressure elements are made, as well as improve the quality of products in the petrochemical and chemical industries.

This paper presents a new measurement technique that enables significant improvement in the dynamics of the industrial thermometer. By using a thermometer of the new design, as well as a new data reduction method, the thermometer delay, and time constant can be reduced several times.

\section{Techniques for determining transient fluid temperature}

In this section, two methods for indirect measurements of transient fluid temperature are presented. First, the thermometer is approximated by the first or second order inertial models and then the inverse heat conduction problem is solved to determine fluid temperature.

\subsection{Considering thermometer to be a first and second order inertia device}

Usually, the thermometer is modelled as an element with lumped thermal capacity. In this way, it is assumed that the temperature of the thermometer is only the function of time, and temperature differences occurring within the thermometer are neglected. The temperature changes of the thermometer in time $T(t)$ have been described by an ordinary first order differential equation (first order thermometer model) $[1,2]$

$\tau \frac{\mathrm{d} T(t)}{\mathrm{d} t}+T(t)=T_{f}(t)$ 
For thermometers with a complex structure used for measuring the temperature of the fluid under high pressure, the accuracy of the first order model (1) is inadequate. To take into account that the temperature sensor readings are delayed when a transient fluid temperature is measured with heavy thermometers, the second order model will be used. In this case, thermometer can be modelled using the ordinary differential equation of the second order which can be written in the form $[8,9]$ :

$\tau_{1} \tau_{2} \frac{\mathrm{d}^{2} T(t)}{\mathrm{d} t^{2}}+\left(\tau_{1}+\tau_{2}\right) \frac{\mathrm{d} T(t)}{\mathrm{d} t}+T(t)=T_{f}(t)$

Equations (1) and (2) were solved for the step increase of the fluid temperature from $T_{0}=0{ }^{\circ} \mathrm{C}$ to the constant value $T_{f}$. The initial conditions are:

$T(0)=T_{0}=0$

$\left.\frac{\mathrm{d} T(t)}{\mathrm{d} t}\right|_{t=0}=v_{T}=0$

The initial problem (2)-(4) was solved using the Laplace transformation and the temperature as a function of time is expressed by the following formula

$u(t)=\frac{T(t)}{T_{f}}=1+\frac{\tau_{1}}{\tau_{2}-\tau_{1}} \exp \left(-\frac{t}{\tau_{1}}\right)-\frac{\tau_{2}}{\tau_{2}-\tau_{1}} \exp \left(-\frac{t}{\tau_{2}}\right)$

In the same way, the initial problem expressed by Eqs. (1) and (3) was solved. For the first order model the thermometer response for a unit step fluid temperature change is determined by the simple expression:

$u(t)=\frac{T(t)}{T_{f}}=1-\exp \left(-\frac{t}{\tau}\right)$

The time constant $\tau$ in Eq. (6) and time constants $\tau_{1}$ and $\tau_{2}$ in Eq. (5) will be estimated from experimental data.

The fluid temperature can be determined based on the measured history of the thermometer temperature $T(t)$ and known time constant $\tau$ using Eq. (1) or time constants $\tau_{1}$ and $\tau_{2}$ when using Eq. (2).

\subsection{Inverse marching method}

An inverse space marching method is used to determine the temperature distribution inside the thermometer and the fluid temperature. The transient heat conduction equation for a cylindrical wall is [8]

$c(T) \rho(T) \frac{\partial T}{\partial t}=\frac{1}{r} \frac{\partial}{\partial r}\left[k(T) r \frac{\partial T}{\partial r}\right] 0 \leq r \leq r_{\text {out }}$

Based on the temperature $T_{1}(t)$ measured at the cylinder axis $r=0$
$T(r=0)=T_{1}(t)$

the temperature distribution inside the cylinder including the outer surface will be determined.

The unknown fluid temperature $T_{f}(t)$ appears in the convective boundary condition at the outer surface of the cylinder

$\left.k(T) \frac{\partial T}{\partial r}\right|_{r=r_{\text {out }}}=h\left(T_{f}-\left.T\right|_{r=r_{\text {out }}}\right)$

The solution of the inverse problem $(7,8)$ is obtained by using the Finite Volume Method (FVM) [13].

The Finite Volume Method (FVM), also called control volume method, is a universal and effective method for solving heat conduction problems. Assuming that the temperature field is two-dimensional and thermal properties $c, \rho, \lambda$ and power density of internal heat sources $\dot{q}_{v}$ are temperature dependent, then heat conduction equation is as follows

$c(T) \rho(T) \frac{\partial T}{\partial t}=-\nabla \cdot \dot{\mathbf{q}}+\dot{q}_{v}$.

Once Eq. (10) is integrated over the control volume $(\mathrm{CV})$, the following equation for a single cell (CV) is obtained:

$\int_{C V} c(T) \rho(T) \frac{\partial T}{\partial t} \mathrm{~d} V=-\int_{C V} \nabla \cdot \dot{\mathbf{q}} \mathrm{d} V+\int_{C V} \dot{q}_{v} \mathrm{~d} V$.

Applying the Green theorem to the first term on the right-hand-side of Eq. (11) gives

$\int_{C V} c(T) \rho(T) \frac{\partial T}{\partial t} \mathrm{~d} V=-\int_{C S} \mathbf{n} \cdot \dot{\mathbf{q}} \mathrm{d} S+\int_{C V} \dot{q}_{v} \mathrm{~d} V$,

where $C S$ is the control volume surface, while $\mathbf{n}$ a normal unit surface vector directed to the outside of the control volume. If $\Delta V_{i}$ designates the volume of a control cell, the individual terms in Eq. (12) can be approximated in the following way:

$\int_{C V} c(T) \rho(T) \frac{\partial T}{\partial t} \mathrm{~d} V \approx \Delta V_{i} c\left(T_{i}\right) \rho\left(T_{i}\right) \frac{\mathrm{d} T_{i}}{\mathrm{~d} t}$

$-\int_{C S} \mathbf{n} \cdot \dot{\mathbf{q}} \mathrm{d} S=\sum_{i=1}^{n} \dot{Q}_{i, j}$

$\int_{C V} \dot{q}_{v} \mathrm{~d} V=\Delta V_{i} \dot{q}_{v}\left(T_{i}\right)$ 


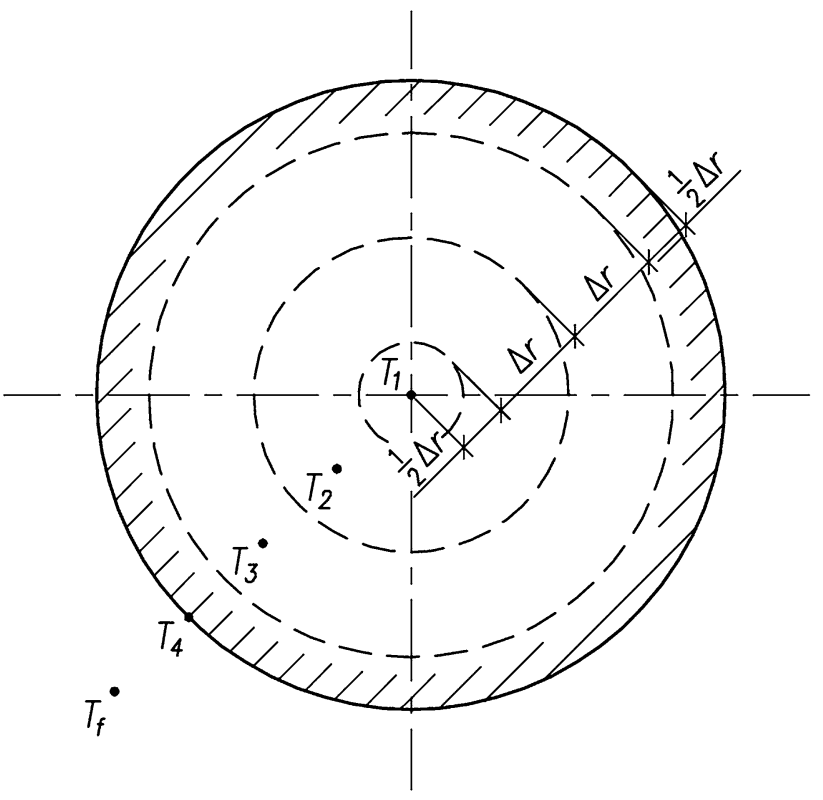

Fig. 1 Division of the cylindrical thermometer into four control volumes

where $\dot{Q}_{i, j}$ is the heat flow that is transferred from the node $j$ located inside the neighbouring cell and the node $i$.

The node $i$ is located inside the analyzed region. Given that heat transfer takes place with the $n$ control volumes adjacent to the analyzed control domain, and taking into account Eqs. (14) and (15), Eq. (13) can be written as:

$\Delta V_{i} c\left(T_{i}\right) \rho\left(T_{i}\right) \frac{\mathrm{d} T_{i}}{\mathrm{~d} t}=\sum_{j=1}^{n_{c}} \dot{Q}_{i, j}+\Delta V \dot{q}_{v}\left(T_{i}\right)$

The thermometer housing is modelled as a solid cylindrical without an inner hole, divided into four control volumes (Fig. 1). The temperature sensor is placed at the axis of the cylinder. Temperatures in the nodes $\mathbf{2 , 3}$ and $\mathbf{4}$ are calculated based only on the temperature measured at node 1 solving the inverse heat conduction problem.

Applying the FVM, the energy balance equations can be written for all nodes which are located at the centres of the control volumes. The energy balance equations are written for the nodes: $\mathbf{1}, \mathbf{2}$, and $\mathbf{3}$ of the control volumes. Taking into account that the temperature $T_{1}(t)$ at the node 1 is measured, the temperature at the node $\mathbf{2}$ is determined form the energy balance equation for the node $\mathbf{1}$. In a similar way, the temperature at the node $\mathbf{3}$ is obtained from the energy balance equation for the node $\mathbf{2}$, and subsequently the temperature at the node $\mathbf{4}$ from the energy balance equation for the node 3 . The thickness of the control volume adjacent to the outer surface of the cylinder is equal to $\Delta r / 2$. Such arrangement of nodes ensures equal distance $\Delta r$ between all nodes. Furthermore, the temperature of the thermometer surface can be determined with higher accuracy, if the node $\mathbf{4}$ is located on the thermometer surface. The location of the node $\mathbf{4}$ on the cylinder boundary facilitates the formulation of the boundary condition (9) in a discrete form. The temperatures at the nodes $\mathbf{2 , 3}$, and $\mathbf{4}$ are as follows:

$$
\begin{aligned}
& T_{2}=T_{1}+\frac{1}{2} \frac{(\Delta r)^{2}}{k\left(T_{1}\right)+k\left(T_{2}\right)} c\left(T_{1}\right) \rho\left(T_{1}\right) \frac{\mathrm{d} T_{1}}{\mathrm{~d} t} \\
& T_{3}=T_{2}-\frac{1}{3} \frac{k\left(T_{1}\right)+k\left(T_{2}\right)}{k\left(T_{3}\right)+k\left(T_{2}\right)}\left(T_{1}-T_{2}\right)+\frac{4}{3}(\Delta r)^{2} \frac{c\left(T_{2}\right) \rho\left(T_{2}\right)}{k\left(T_{3}\right)+k\left(T_{2}\right)} \frac{\mathrm{d} T_{2}}{\mathrm{~d} t} \\
& T_{4}=T_{3}-\frac{3}{5} \frac{k\left(T_{2}\right)+k\left(T_{3}\right)}{k\left(T_{4}\right)+k\left(T_{3}\right)}\left(T_{2}-T_{3}\right)+\frac{8}{5}(\Delta r)^{2} \frac{c\left(T_{3}\right) \rho\left(T_{3}\right)}{k\left(T_{4}\right)+k\left(T_{3}\right)} \frac{\mathrm{d} T_{3}}{\mathrm{~d} t}
\end{aligned}
$$

where the symbol $\Delta r=r_{\text {oul }} / 3$.

The energy balance equation for the node 4 is

$$
\begin{aligned}
& \pi\left[r_{\text {out }}^{2}-\left(r_{\text {out }}-\frac{\Delta r}{2}\right)^{2}\right] c\left(T_{4}\right) \rho\left(T_{4}\right) \frac{\mathrm{d} T_{4}}{\mathrm{~d} t} \\
& \quad=2 \pi\left(r_{\text {out }}-\frac{\Delta r}{2}\right) \frac{k\left(T_{3}\right)+k\left(T_{4}\right)}{2} \frac{T_{3}-T_{4}}{\Delta r}+2 \pi r_{\text {out }} h\left(T_{f}-T_{4}\right)
\end{aligned}
$$

Solving Eq. (20) gives the fluid temperature $T_{f}(t)$

$T_{f}=T_{4}-\frac{5}{12} \frac{k\left(T_{3}\right)+k\left(T_{4}\right)}{h \Delta r}\left(T_{3}-T_{4}\right)+\frac{11}{24} \Delta r \frac{c\left(T_{4}\right) \rho\left(T_{4}\right)}{h} \frac{\mathrm{d} T_{4}}{\mathrm{~d} t}$

The surface temperature $T_{f}$ is determined sequentially. Calculating the time derivatives $\mathrm{d} T_{1} / \mathrm{d} t$ and using Eq. (17), the temperature at the node $\mathbf{2}$ is obtained at first. Next, the temperatures at the nodes $T_{3}$ and $T_{4}$ are calculated in sequence using Eqs. (18) and (19).

Values of thermal conductivity $k\left(T_{i}\right)$ for temperature $T_{i}$ at the $i$ node (where $i=2,3,4$ ) are unknown. It is necessary to execute several iterations to obtain temperature $T_{i}$. It was assumed that the starting value of the thermal conductivity for the first iteration is

$k\left(T_{i}^{(0)}\right)=k\left(T_{i-1}\right)$

The iteration continues until

$\left|T_{i}^{(n+1)}-T_{i}^{(n)}\right| \leq \varepsilon, \quad i=2,3,4$

where the small value $\varepsilon$ is equal to $0.00001 \mathrm{~K}$.

The value of $\varepsilon$ must be small enough so that the temperature dependent properties of the thermometer are taken into consideration. Iterative calculations were carried out at different values of tolerance $\varepsilon$. When the values of $\varepsilon$ equal 
to 0.00001 or $0.000001 \mathrm{~K}$, practically the same results were obtained.

Having determined temperatures $T_{2}, T_{3}$, and $T_{4}$, the fluid temperature is calculated using Eq. (21).

\section{Computational validation of the inverse method}

The method developed in the paper was used to determine transient fluid temperature. At first, direct heat conduction problem was solved for two cases: stepwise and linear temperature increase. The temperature $T_{1}(t)$ at the centre of the solid cylinder $r=0$ for sudden temperature increase was calculated using an analytical method [13]. In the case of a linear rise of fluid temperature, the temperature at the centre of the cylinder was determined by Duhamel integral using the solution of the direct heat conduction problem for the unit step change in temperature of the fluid.

The calculations were carried out for a thermometer with an outer diameter of $7 \mathrm{~mm}$ made of 1.4541 steel (austenitic steel), with the following physical properties: $\rho=7.9 \cdot 10^{3}$ $\mathrm{kg} / \mathrm{m}^{3}, k=18 \mathrm{~W} /(\mathrm{m} \mathrm{K}), c=500 \mathrm{~J} /(\mathrm{kg} \mathrm{K})$. The heat transfer coefficient at the outer surface is $h=2000 \mathrm{~W} /\left(\mathrm{m}^{2} \mathrm{~K}\right)$. The cylinder temperature was calculated (direct problem) for the stepwise increase in fluid temperature from 20 to $100{ }^{\circ} \mathrm{C}$ and linear rise from 0 to $170{ }^{\circ} \mathrm{C}$ with temperature change rate equal: $v_{T}=0.33333 \mathrm{~K} / \mathrm{s}$.

Finally, the inverse problem was solved using $T_{1}(t)$ as the input data. The time step size for the inverse analysis was determined from the following condition [13]:

$\Delta t \geq 0.05 r_{\text {out }}^{2} / \kappa$

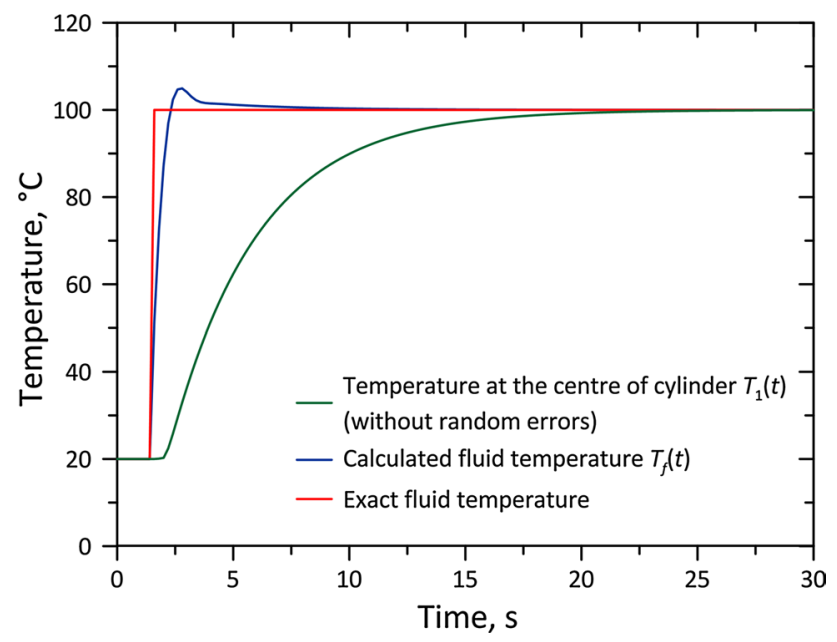

Fig. 2 Fluid temperature obtained from the inverse solution and temperature at the centre of thermometer with the diameter of $7 \mathrm{~mm}$ (input data) - comparison of the exact fluid temperature with the results obtained from the solution of the inverse problem for the stepwise increase in fluid temperature

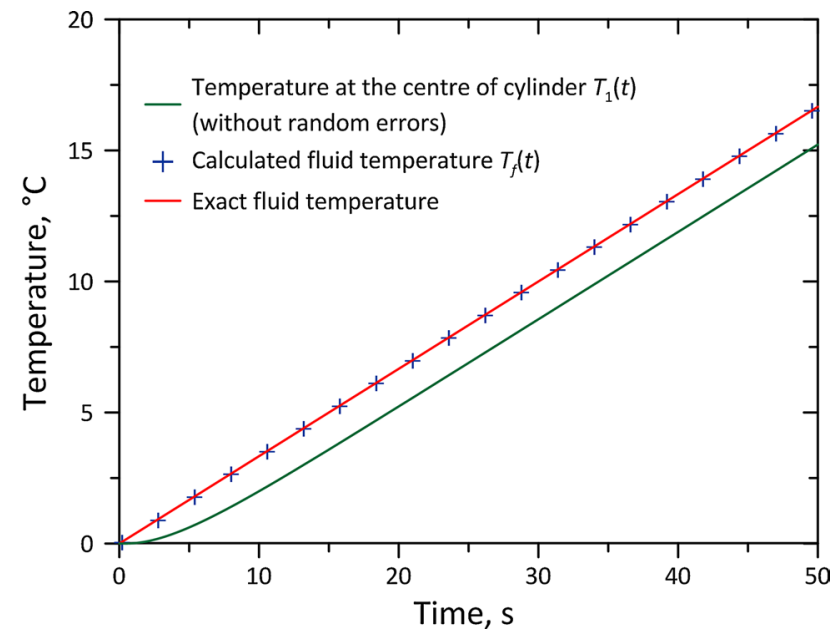

Fig. 3 Fluid temperature obtained from the inverse solution and temperature at the centre of thermometer with the diameter of $7 \mathrm{~mm}$ (input data)-comparison of the exact temperature with the results obtained from the solution of the inverse problem for linear rise in fluid temperature

and its value was assumed $0.2 \mathrm{~s}$. The symbol $\kappa$ in Eq. (24) stands for the thermal diffusivity: $\kappa=k /(c \rho)$.

Results of calculations of time temperature changes at the centre of the thermometer obtained by the exact analytical method and the inverse method are presented in Figs. 2 and 3 .

An analysis of the results depicted in Figs. 2 and 3 shows that very good coincidence of the fluid temperature determined by the inverse method with exact fluid temperature.

\section{Experimental study}

Experimental studies included measurement of water and transient air temperature. Two thermometers were used, both with a housing diameter of $15 \mathrm{~mm}$, but of different construction. Measurements were carried out using the developed thermometer and an industrial thermometer. Time constants of the industrial thermometer were determined while the water or air temperature was measured. In the first experiment, the test thermometer was suddenly immersed in boiling water to determine its time constants. Next, the time constant of the thermometer was determined in air flowing at different velocities.

The first gauge is an industrial thermometer widely available commercially. The housing of thermometer having an inner diameter of $9 \mathrm{~mm}$ is made of $1 \mathrm{H} 18 \mathrm{~N} 9 \mathrm{~T}$ austenitic steel. The chemical composition of the steel is as follows: $0.1 \% \mathrm{C}, 18 \% \mathrm{Cr}, 9 \% \mathrm{Ni}, 2 \% \mathrm{Mn}, 0.8 \% \mathrm{Si}$, $0.045 \% \mathrm{P}$, and $0.03 \% \mathrm{~S}$. The temperature sensor is a $\mathrm{K}$ type thermocouple (NiCr-NiAl). Two wires with a diameter of $0.5 \mathrm{~mm}$ each form a thermocouple. Hot junction of 
the thermocouple is not grounded. Six ceramic cylinders of $6 \mathrm{~mm}$ diameter and $50 \mathrm{~mm}$ length are inserted into the thermometer pocket. There are four holes with a diameter of $1 \mathrm{~mm}$ in the cross-section of the each ceramic cylinder, and only through two holes thermocouple wires are conducted. There is a gap of $1.5 \mathrm{~mm}$ between ceramic cylinders and the inner surface of the thermometer thermowell.

The second thermometer of the new design has a cylindrical casing of external diameter $15 \mathrm{~mm}$, inside which a hole with a diameter of $1.1 \mathrm{~mm}$ is drilled. The outer diameter of the sheath thermocouple inserted into the inner hole is $1 \mathrm{~mm}$. The thermometer presented in this paper is characterized by a very small air gap between the thermocouple sheath and the surface of the hole drilled axially throughout the solid cylinder. The thermocouple of $\mathrm{K}$ type with the grounded junction is used to measure temperature. The thermowell is made of $1 \mathrm{H} 18 \mathrm{~N} 9 \mathrm{~T}$ stainless steel.

The temperature sensors used in the experiment have been calibrated in the temperature range from 25 to $120^{\circ} \mathrm{C}$ in a calibration oven to obtain their characteristics.

\subsection{Water temperature measurement}

In the experiments, the saturated water temperature was measured using the developed and industrial thermometer. Thermometers at room temperature were suddenly immersed in boiling water. In addition, the water temperature was measured by a bare sheath thermocouple having a diameter of $1.5 \mathrm{~mm}$. The $\mathrm{K}$ type sheath thermocouple was used to measure the water temperature continuously during

(a)

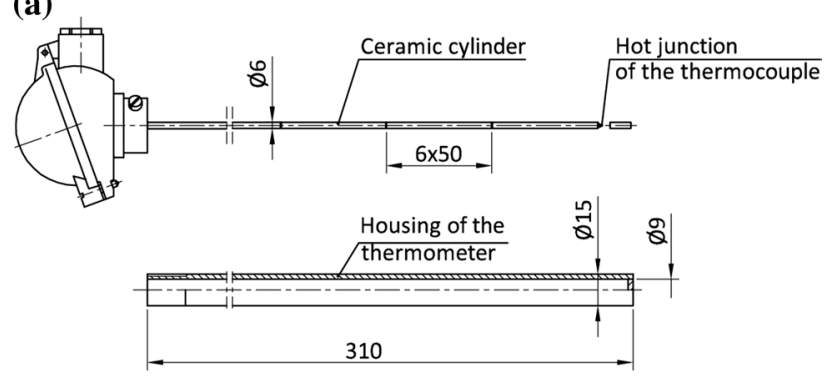

(b)

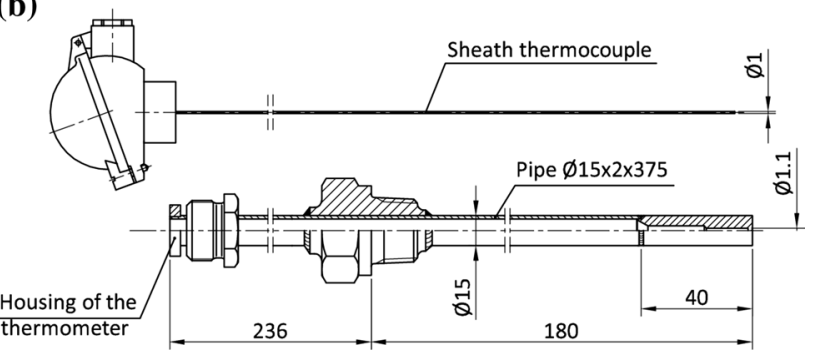

Fig. 4 View of the thermometers: a industrial thermometer, $\mathbf{b}$ new design thermometer the experiment. The time constant of the thermocouple is low due to its small diameter (Fig. 4).

The temperature indicated by the thermometer sensors are shown in Fig. 5.
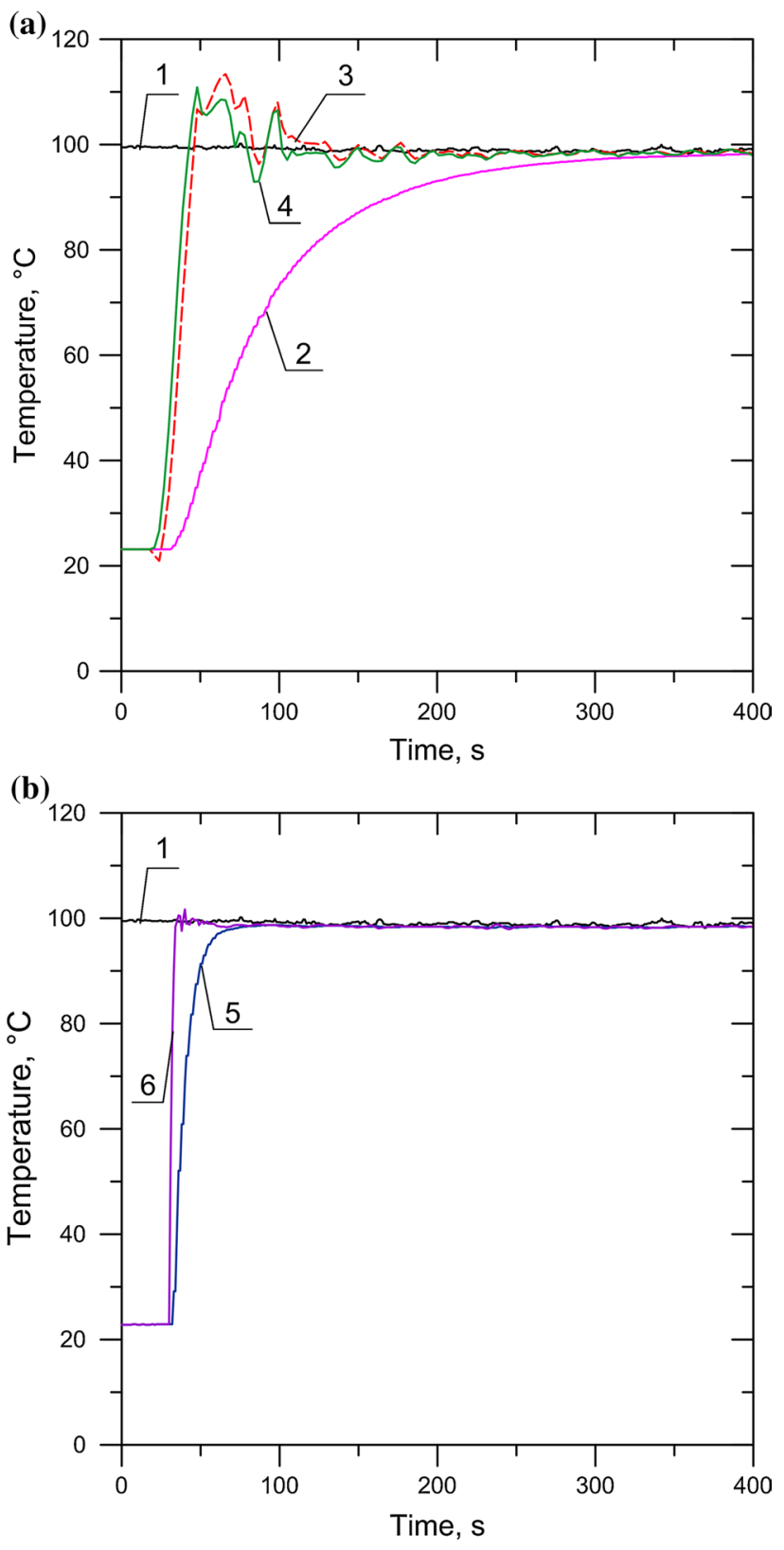

Fig. 5 Comparison of the fluid temperature obtained using various techniques with indications of the thermocouple with an outer diameter of $1.5 \mathrm{~mm}$ (plot 1) and: a industrial thermometer: 2-temperature indicated by the industrial thermometer with heavy thermowell, 3fluid temperature calculated by Eq. (1) based on measured temperature 2, 4-fluid temperature calculated by Eq. (2) based on measured temperature 2; b thermometer with new housing: 5-temperature indicated by the thermometer with new housing, 6-fluid temperature calculated using the inverse marching method 
The measurement of transient temperature by the industrial thermometer has a very big dynamic error. To reduce this error, mathematical model of the first and second order was used to calculate water temperature. For this purpose, the time constant $\tau$ was determined for the model of the first order and for the second order model two time constants $\tau_{1}$ and $\tau_{2}$ were determined. Based on water temperature measurement the time constant $\tau$ was found to be: $\tau=67.156 \pm 0.484 \mathrm{~s}$. The time constants for the thermometer considered as the second order model are: $\tau_{1}=5.360 \pm 0.334 \mathrm{~s}$ and $\tau_{2}=61.399 \pm 0.445 \mathrm{~s}$.

The $95 \%$ uncertainties in the calculated time constants were estimated using the variance propagation rule formulated by Gauss [14]. The mean square error $s_{N}$ of the measured temperature was assumed equal for all measuring time points and calculated using the formula:

$s_{N}=\sqrt{\frac{S_{\min }}{N-m}}$,

where $m$ is the number of time constants and $N$ denotes the number of time points in a measurement series. The symbol $S_{\min }$ designates the minimum sum of squares of differences between measured and calculated temperatures.

The fluid temperature $T_{f}(t)$ was determined using Eqs. (1) and (2). To eliminate the random errors inherent to actual temperature measurements and to determine the first and second order derivatives of measured temperature with respect to time, a 9 point digital filter was used [15]. The results of the calculations are shown in Fig. 5a.

The proposed thermometer had much better dynamic properties when water temperature was measured in comparison with a conventional thermometer. The temperature measurement made by the thermometer with the housing proposed is burdened with much smaller dynamic error compared to the measurement made by the industrial thermometer (Fig. 5b). Even for quicker response of the thermometer and more accurate measurements, an inverse marching method was applied. Equations (17)(19) and (21) were used to obtain the water temperature. Calculations were conducted for constant physical properties of the thermometer housing: specific heat $c=500 \mathrm{~J} /$ $(\mathrm{kg} \mathrm{K})$, density $\rho=7900 \mathrm{~kg} / \mathrm{m}^{3}$ and thermal conductivity $k=18 \mathrm{~W} /(\mathrm{m} \mathrm{K})$. Heat transfer coefficient on the outer surface of the thermometer was $h=2381 \mathrm{~W} /\left(\mathrm{m}^{2} \mathrm{~K}\right)$. The results of the calculations are shown in Fig. $5 \mathrm{~b}$.

The fluid temperatures obtained by using a conventional thermometer in conjunction with the first and second order thermometer model and by using developed thermometer in combination with the inverse method are compared with the reference temperature measured by a thermocouple with the outer diameter of $1.5 \mathrm{~mm}$ (Figs. 5 and 6).

The analysis of the results depicted in Figs. 5 and 6 show that the technique proposed for measuring the fluid

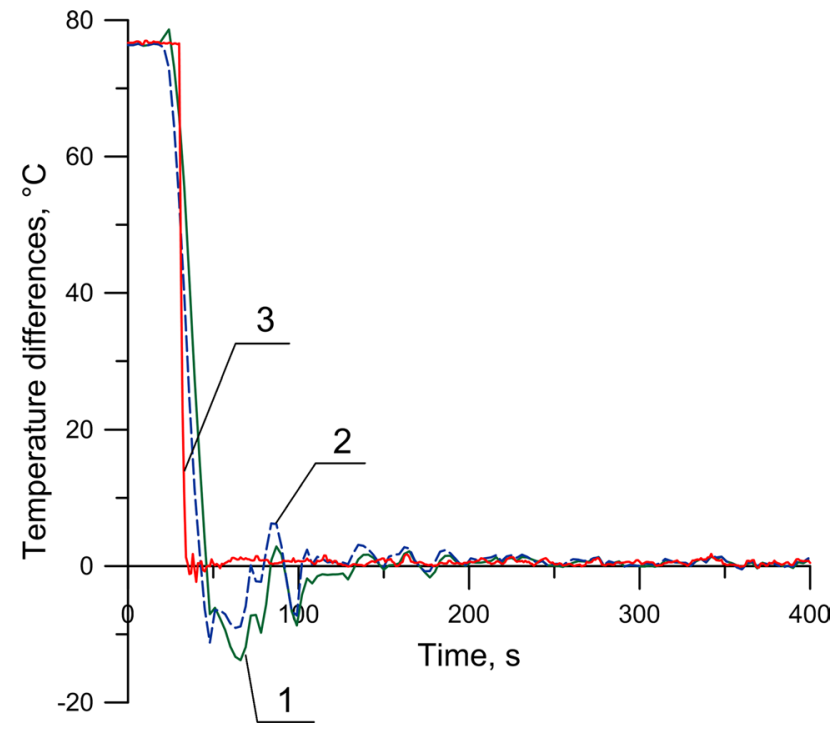

Fig. 6 Comparison of two methods used to reduce dynamic errors of transient fluid temperature measurement: 1-temperature difference between the reference temperature measured by the thermocouple with outer diameter of $1.5 \mathrm{~mm}$ and fluid temperature calculated by Eq. (1), 2-temperature difference between the reference temperature and fluid temperature calculated by Eq. (2), 3-temperature difference between the reference temperature and fluid temperature calculated using the inverse marching method

temperature by the new thermometer is much more accurate. The conventional thermometer has a large inertia and even temperature correction using the model of the first or second order does not give satisfactory results.

\subsection{Air temperature measurement}

At first, the time constants of the industrial thermometer $\tau$ for various air velocities $w$ were determined in an open benchtop wind tunnel (Fig. 7). The WT4401-S benchtop wind tunnel is designed to give uniform flow rate over a $100 \mathrm{~mm} \times 100 \mathrm{~mm}$ cross section (WT4401-S \& WT4401D Benchtop Wind Tunnels).

Based on the thermometer response for a step change in air temperature, the time constants for different air velocities were determined using the first order thermometer model. The time constant of a conventional thermometer that was estimated experimentally is shown in Fig. 8 as a function of air velocity. The experimental data were approximated by the least squares method. The experimental data very well approximates the following function (Fig. 8):

$\tau=\frac{1}{0.0018215+0.0012272 \sqrt{w}}$

where $\tau$ is expressed in s, and $w$ in $\mathrm{m} / \mathrm{s}$. 


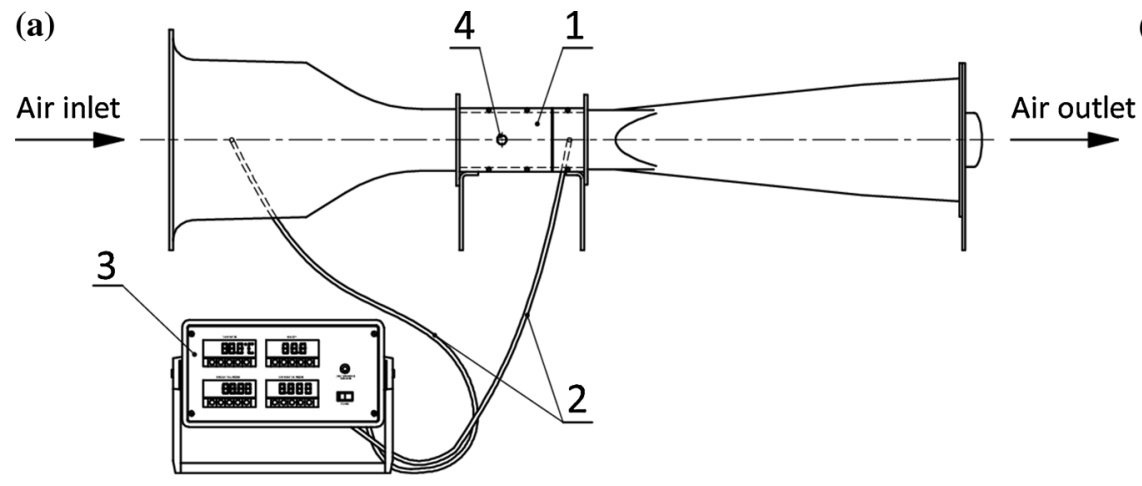

(b)

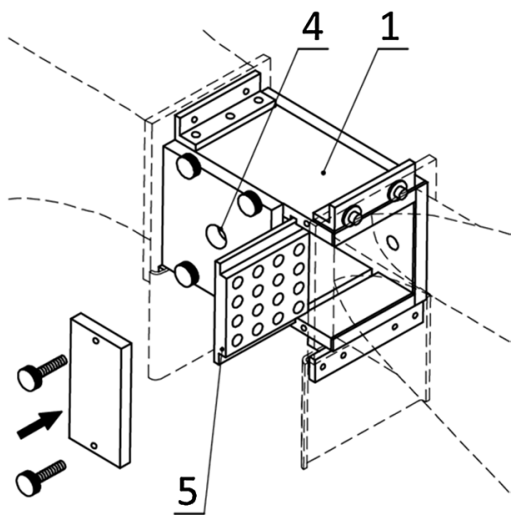

Fig. 7 Wind tunnel used for determining thermocouple time constant a overall view b restrictive plate placement [16]: 1-test chamber with opening for the thermometer; 2-differential pressure measurement;

3-data acquisition system, 4-opening for the thermometer insertion, 5-restrictive plate for adjusting velocity measurement range
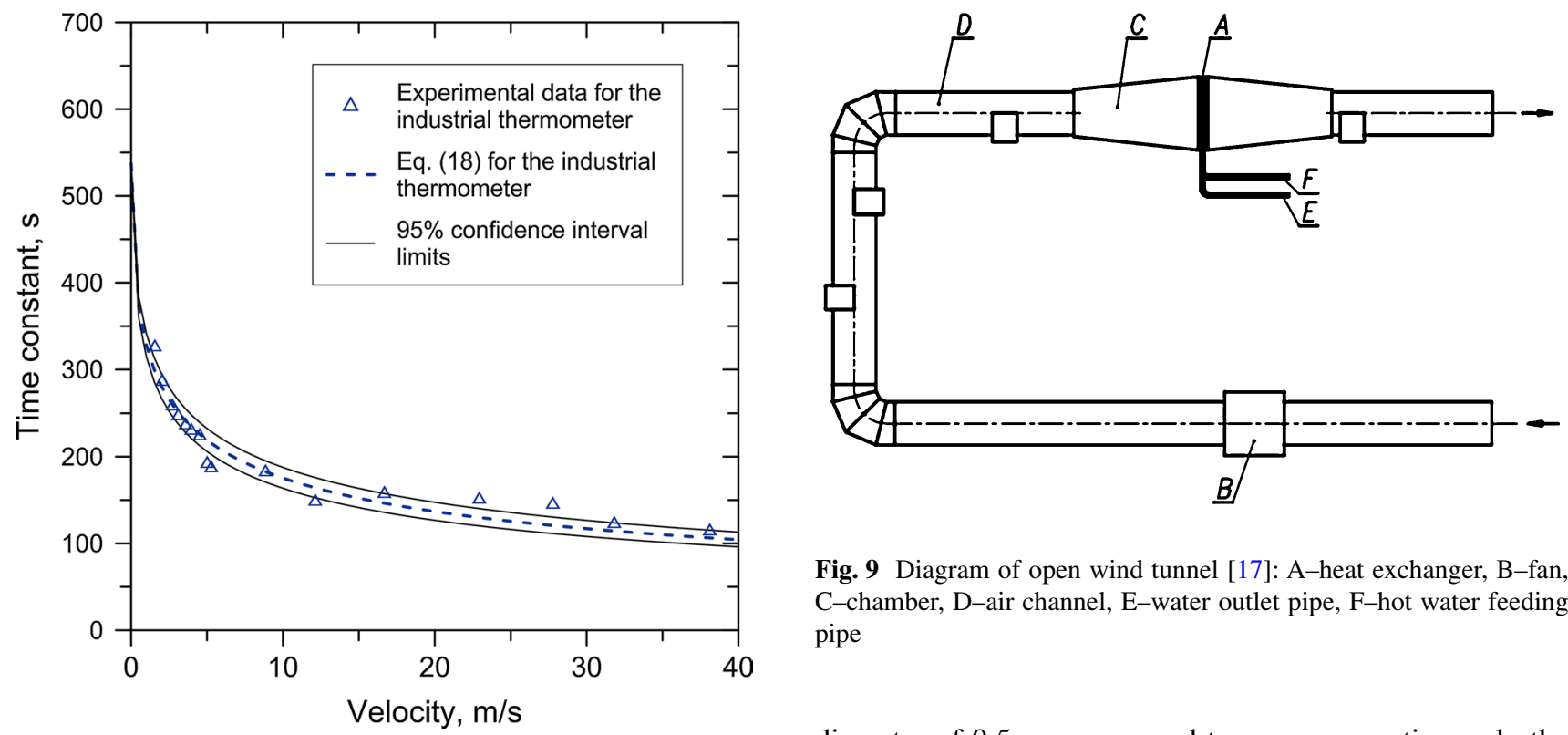

Fig. 9 Diagram of open wind tunnel [17]: A-heat exchanger, B-fan, C-chamber, D-air channel, E-water outlet pipe, F-hot water feeding pipe

diameter of $0.5 \mathrm{~mm}$ was used to measure continuously the air temperature behind a heat exchanger (Fig. 9).

By the sudden drop in air velocity of $2.5-1.1 \mathrm{~m} / \mathrm{s}$, the

Fig. 8 Time constant $\tau$ of the industrial as a function of air velocity $w$ with $95 \%$ confidence interval limits

Next, the transient temperature in the wind tunnel (Fig. 9) was measured. Two thermometers described in Subsection 4 were used, both with a housing diameter of $15 \mathrm{~mm}$.

First, the measurements were made using the industrial thermometer and then using a newly designed thermometer. The air in the tunnel was heated by a heat exchanger, and its velocity was also varied. The thermometers measured the temperature behind the heat exchanger. The air velocity was measured by the vane anemometer. Both the velocity and temperature data were collected using the Ahlborn ALMEMO 5990-0 data acquisition system. Also, the calibrated $\mathrm{K}$ type sheath thermocouple with an outer air temperature after the heat exchanger increased from 48 to $55{ }^{\circ} \mathrm{C}$ (Fig. 10). Indications of a thermocouple located inside the industrial thermometer are significantly delayed and damped with respect to changes in air temperature. Similar behavior is observed for the thermocouple inside of the proposed thermometer (Fig. 11). As a result of a decrease in air velocity of $2.5-1.0 \mathrm{~m} / \mathrm{s}$ the air temperature after heat exchanger rose from 47 to $54{ }^{\circ} \mathrm{C}$. The air-site heat transfer coefficient on the outer surface of the housing of the thermometer is small. With such a small heat transfer coefficient heating of the commercial thermometer and the developed thermometer is very slow. From the comparison of the results of measurements shown in the Figs. 10 and 11 can be seen that there are no major differences in the time of heating of the thermocouple inside the thermometer. 
Fig. 10 Measurements and results of calculations: $1-$ temperature measured by the industrial thermometer, 2-temperature measured by the thermocouple with outer diameter of $1.5 \mathrm{~mm}$, 3-temperature calculated using the inverse method based on measurements carried out by the industrial thermometer, 4-time constant of the thermometer, 5-velocity of the air

Fig. 11 Measurements and results of calculations: $1-$ temperature measured by the designed thermometer, 2temperature measured by the thermocouple with an outer diameter of $1.5 \mathrm{~mm}$, 3-temperature calculated using the inverse method based on measurements carried out by the proposed thermometer, 4-heat transfer coefficient on the outer surface of the thermometer, 5-air velocity
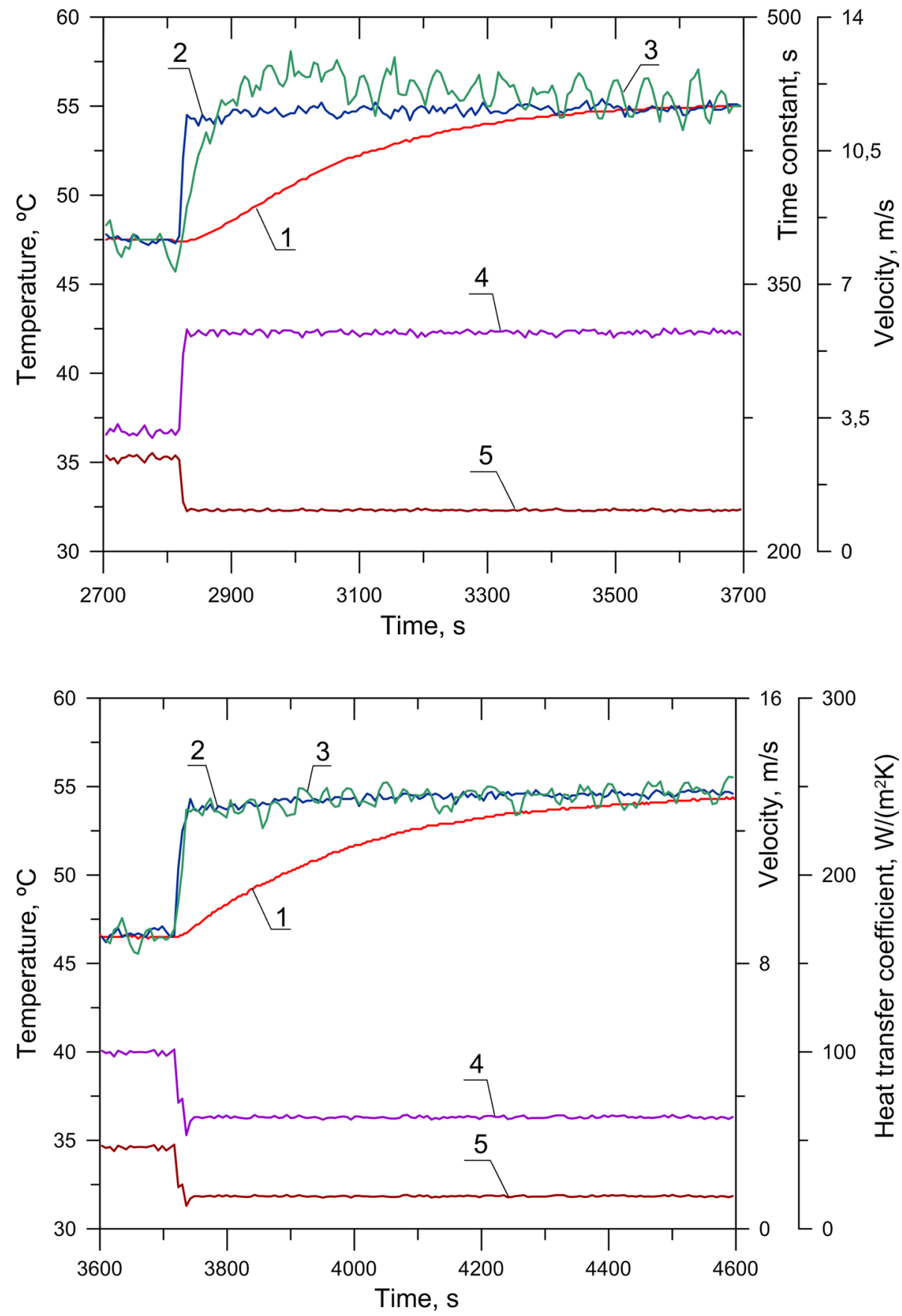

Based on measurements, the transient temperature of the air was determined assuming that the industrial thermometer is an inertial object of the first order. Calculating the time constant from Eq. (25) and using Eq. (1) the air temperature was estimated. Because the air velocity varied in time, the time constant of the thermometer is also a function of time. The computations were performed for the sampling time $\Delta t=6 \mathrm{~s}$. The results of the calculations are shown in Fig. 10.

Then, the transient air temperature was measured using a new thermometer. To determine the temperature of the air more accurate data reducing method was used. The physical properties of the thermowell material are the same as in the case of measuring the water temperature.

Different correlations may be used to calculate the heat transfer coefficient on the outer surface of the thermometer $[18,19]$. In this paper, the heat transfer coefficient on the outer surface of the thermometer housing in the Eq. (21) was calculated from the relationship:

$\mathrm{Nu}_{a}=1.3 \operatorname{Re}_{a}^{0.5} \operatorname{Pr}_{a}^{0.31}, \quad 10^{2} \leq \operatorname{Re}_{a} \leq 10^{4}$ 
where: $\mathrm{Nu}_{a}=h d / k_{a}, \operatorname{Re}_{a}=w d / v_{a}$ and $\operatorname{Pr}_{a}=c_{p a} \mu_{a} / k_{a}$.

The inverse marching method given by Eq. (17)-(19) and (21) was applied for determining the air temperature. The following physical properties of the air were used in the evaluation of the heat transfer coefficient: Prandtl number $\operatorname{Pr}_{a}=0.698$, thermal conductivity $k_{a}=0.0283 \mathrm{~W} /(\mathrm{m}$ $\mathrm{K})$, and kinematic viscosity $v_{a}=17.95 \cdot 10^{-6} \mathrm{~m}^{2} / \mathrm{s}$. The calculations were made with the time step of $6 \mathrm{~s}$.

An inspection of results depicted in Fig. 11 shows that the proposed measuring technique gives the air temperature that is very close to the temperature measured using a thin thermocouple.

\section{Conclusions}

Both methods presented in the paper allow for the accurate measurements of transient fluid temperature but are suitable for different applications. The first method is suitable for measuring gas temperature, e.g. the temperature of the flue gas or air when the temperature is measured using thin bare thermocouples. The second technique based on the solution of the inverse heat conduction problem is more appropriate for measuring the fluid temperature at high pressure and temperature, e.g. water or steam in boilers, pipelines or turbines. By comparing the measurement results, it was demonstrated that the proposed measuring technique allows obtaining the real fluid temperature much faster compared to industrial thermometers. Accurate measurement of fast fluid temperature changes is possible due to the designed low inertia thermometer and fast space marching method for solving inverse heat conduction problem. The fluid temperature is calculated on the basis of temperature indicated by the thin thermocouple located at the axis of the cylindrical thermometer.

The results presented in the paper are very important from a practical point of view. Using the inverse method for transient fluid temperature measurement proposed in the paper, the start-up of steam boilers and steam or gas turbines can be carried out in the right way. Using the method developed for measuring the temperature of the fluid can greatly improve the quality of temperature control of superheated steam, flue gases, etc.

The measuring technique is simple, yet accurate. Assuming that the heat transfer coefficient can be calculated from available in literature heat transfer correlations, the fluid temperature can be calculated in on-line mode. The advantage of the inverse method is the independence of the results from the initial temperature distribution in the thermometer. This is very important because if the previous measurement data are lost, temperature measurement can be carried further after picking the first four points. The experimental test, which has been carried out, illustrates the good accuracy of the method and its computational efficiency.

Acknowledgments The results presented in this paper were obtained from research work co-financed by the National Centre for Research and Development in the framework of the contract PBS1/A4/4/2012Applied Research Program-Development of advanced methods to assess the residual life of pressure elements in power plants.

Open Access This article is distributed under the terms of the Creative Commons Attribution 4.0 International License (http://creativecommons.org/licenses/by/4.0/), which permits unrestricted use, distribution, and reproduction in any medium, provided you give appropriate credit to the original author(s) and the source, provide a link to the Creative Commons license, and indicate if changes were made.

\section{References}

1. Michalski L, Eckersdorf K, Kucharski J, McGhee J (2001) Temperature measurement, 2nd edn. Wiley, Chichester

2. Kerlin TW, Johnson M (2012) Practical thermocouple thermometry, 2nd edn. International Society of Automation, Research Triangle Park, NC

3. Heiland HG, Wozniak G, Wozniak K (2007) Flow and temperature field measurements of thermal convection in a small vertical gap using liquid crystals. Heat Mass Transf 43:863-870

4. Stephan P, Fuchs T (2009) Local heat flow and temperature fluctuations in wall and fluid in nucleate boiling systems. Heat Mass Trans 45:919-928

5. Love J (2007) Process automation handbook. A guide to theory and practice, chapter 16: temperature measurement. Springer, Berlin, pp 99-106

6. ASME PTC 19.3 TW-210 Thermowells. Performance test codes, an American national standard, The American Society of mechanical engineers, New York, 2010

7. Johnson MP, Gilson AG (2014) Understanding the impact of steam cleanout on thermowell installations. Flow Control 6:14 17. www.FlowControlNetwork.com

8. Jaremkiewicz M (2012) Inverse heat transfer problem encountered in measurement of transient fluid temperature. Publishing House of Cracow University of Technology, Cracow (in Polish)

9. Jaremkiewicz M, Taler D, Sobota T (2009) Measuring transient temperature of the medium in power engineering machines and installations. Appl Therm Eng 29:3374-3379

10. Tomczuk K, Werszko R (2013) Correction for thermal lag in dynamic temperature measurements using resistance thermometers. Rev Sci Instrum 84:074903-1-074903-7

11. Taler D, Taler J (2009) Optimum heating of thick plate. Int J Heat Mass Transf 52:2335-2342

12. Taler J, Dzierwa P, Taler D, Harchut P (2015) Optimization of the boiler start-up taking into account thermal stresses. Energy. doi:10.1016/j.energy.2015.03.095

13. Taler J, Duda P (2006) Solving direct and inverse heat conduction problems. Springer, Berlin

14. Seber GAF, Wild CJ (1989) Nonlinear regression. Wiley, New York

15. Taler J (1995) Theory and practice of identification of heat transfer processes. Zakład Narodowy imienia Ossolińskich, Wrocław (in Polish) 
16. WT4401-S\&WT4401-D Benchtop wind tunnels. Omega, Stamford, CT, USA. www.omega.com

17. Taler D (2013) Experimental determination of correlations for average heat transfer coefficients in heat exchangers on both fluid sides. Heat Mass Transf 49:1125-1139
18. Nakamura H, Igarashi $\mathrm{T}$ (2004) Variation of Nusselt number with flow regimes behind a circular cylinder for Reynolds numbers from 70 to 30,000. Int J Heat Mass Transf 47:5169-5173

19. Favre-Marinet M, Tardu S (2009) Convective heat transfer. John Wiley \& Sons, Hoboken 